\title{
Un espacio de resguardo y resistencia no violenta bajo la dictadura cívico- militar: El Boletín de Derechos Humanos de la Pastoral de Derechos Humanos del Arzobispado de la Santísima Concepción (1986-1989)
}

\author{
Danny Monsálvez Araneda \\ Universidad de Concepción, Concepción, Chile. \\ Email:monsalvez@gmail.com \\ León Pagola Contreras \\ Universidad de Concepción, Concepción, Chile. \\ Email: leonpagola@gmail.com
}

\begin{abstract}
Resumen: ${ }^{1}$ Durante la dictadura cívico-militar que gobernó Chile durante 17 años las formas de oposición en contra del régimen adquirieron diversas y variadas expresiones de resistencia y denuncia, siendo el tema de la sistemática violación a los derechos humanos el aspecto más visible y reconocible de todos aquellos actores, grupos y movimientos que fueron víctimas de la violencia institucional de la dictadura. En vista de aquello el presente artículo busca situar el Boletín de Derechos Humanos del Arzobispado de la Santísima Concepción como uno de los principales espacios de resguardo y resistencia no violenta de lo que fue la labor pastoral, desarrollada por la Iglesia Católica durante la década de los ochenta en favor de quienes fueron perseguidos por los aparatos represivos de régimen en el Gran Concepción. La construcción de este espacio de oposición a la dictadura, así como la creación de un conocimiento sobre el tema de la violencia, represión y tortura, dieron paso a una lucha en favor de quienes estaban siendo asediados por la dictadura de Pinochet. En ese sentido, el Boletín de Derechos Humanos fue un espacio de denuncia, también de resguardo, resistencia y de llamado a la acción no violenta por parte de la ciudadanía.
\end{abstract} rechos humanos.

Palabras clave: Dictadura cívico-militar, Gran Concepción, violencia, de-

An area of shelter and non-violent resistance under the civil-military dictatorship: The Human Rights Newsletter of the Pastorale of Human Rights of the Archdiocese of Santísima Concepción (1986-1989)

Abstract: During the civil-military dictatorship that ruled Chile for 17 
years, forms of opposition against the regime took on diverse and varied expressions of resistance and denunciation, being the topic of systematic violation of human rights the most visible and recognizable aspect of all actors, groups and movements who were victims of state violence of the dictatorship. This article seeks to place the Human Rights Newsletter of the Archbishop of Santísima Concepción as one of the main areas of shelter and nonviolent resistance which was the pastoral work of the Catholic Church during the eighties in favor of those who were persecuted by the repressive regime in the Great Concepción. The construction of this space of opposition to dictatorship and the knowledge creation on the subject of violence, repression and torture, gave way to a struggle in favor of those who were being besieged by the Pinochet dictatorship. The Human Rights Newsletter was a denunciation space, also for protection, resistance and a call for nonviolent action by the citizenship. rights.

Keywords: Civil-military dictatorship, Great Conception, violence, human

\section{Um espaço de abrigo e resistência não-violenta sob a ditadura civil-militar: O Boletim de Direitos Humanos da Pastoral dos Direitos Humanos da Arquidiocese da Santíssima Concepción (1986-1989)}

Resumo: Durante a ditadura civil-militar que governou o Chile por 17 anos as formas de oposição contra o regime adquiriram diversas e variadas expressões de resistência e denúncia, sendo objeto de violação sistemática dos direitos humanos, o aspecto mais visível e reconhecível de todos esses atores, grupos e movimentos que foram vítimas de violência do Estado durante a ditadura. Este artigo pretende colocar o Boletim de Direitos Humanos da Arquidiocese da Santa Conceição como uma das principais áreas de abrigo e resistêncianão-violenta daquilo que foi o trabalho pastoral da Igreja Católica durante a década de oitenta em favor daqueles que foram perseguidos pelo regime repressivo na Grande Concepción. A construção deste espaço de oposição à ditadura, ea criação de um conhecimento sobre o tema da violência, repressão e tortura, deu lugar a uma luta a favor daqueles que estavam sendo assediados pela ditadura de Pinochet. Nesse sentido, o Boletim de Direitos Humanos foi um espaço de denúncia, também de resguardo, resistência e uma chamada àaçãonão-violenta por parte dos cidadãos.

Palavras-chave: ditadura cívico-militar, Grande Concepción, violência, direitos humanos.

\section{Introducción}

Uno de los campos más reconocibles del régimen de Augusto Pinochet dice relación con la sistemática violación de los derechos humanos (Padilla, 1995; Salazar, 2011 y 2012; Insunza y Ortega, 2011 y 2014; Weibel, 2012; Rebolledo, 2012, 2013 y 2015) y la concerniente oposición, resistencia y labor que desempeñaron las diversas agrupaciones de familiares y víctimas de quienes fueron perseguidos, torturados y desaparecidos durante los 17 años de dictadura cívico-militar (Díaz, Sierra y Becerra, 
1997; Orellana y Hutchison, 1991;Vega, 1988 y 1999; Peñaloza, 2011). Estas organizaciones fueron en un primer momento los actores que dieron cuenta de la represión perpetrada por el régimen autoritario; es decir, por una parte se constituyeron en el rostro público de la violencia institucional, y por otro lado, se convirtieron en la vanguardia de la denuncia y oposición a la dictadura pinochetista.

Tras el golpe de Estado de 1973, el espacio público fue violentamente intervenido, ya sea a través de la presencia de militares en las calles, poblaciones, edificios públicos, lugares de trabajo o bien por intermedio de determinadas medidas administrativas emanadas a través de los bandos militares.Por ejemplo el cambio de nombre de poblaciones, campamentos y tomas que hasta el 11 de septiembre de 1973 tenían nombre de personas y personajes vinculados al mundo de la izquierda o bien con la designación de autoridades, como directores de empresas, industrias, colegios, liceos, alcaldes o juntas de vecinos (Garretón, 1998 y Monsálvez, 2014). Lo anterior instituyó un clima de hostilidad, amedrentamiento y miedo entre la población. En otras palabras, la dictadura no sólo avanzó a través de una violencia directa, léase la represión física, también llevó adelante una violencia simbólica y cultural destinada a establecer el disciplinamiento social y el control de los cuerpos y las mentes. Una verdadera regeneración cultural (Errázuriz y Leiva, 2012).

El panorama personal, familiar, laboral, así como la vida en comunidad se vio no solamente intervenida y alterada por la violencia, sino también invisibilizada y acallada por el terror y el miedo imperante, el cual silenció voces, acalló otras y confinó al ciudadano a un espacio privado, alejado de todo quehacer público o visible (Lechner, 2006; Brunner, 1977 y 1980; Araujo y Martuccelli, 2012). En aquel contexto, la labor desempeñada en los inicios de la dictadura por el Arzobispado de la Santísima Concepción, se constituyó en un espacio no solo de reacción y contención frente a los hechos de violencia cometidos por el Estado y sus agentes de seguridad, sino también implicó un proceso de aprendizaje en torno a la desaparición, persecución y tortura; es decir, generó un espacio de enseñanza y educación sobre la importancia de los derechos humanos, el valor y defensa de la vida desde un plano ético cristiano.

En aquel contexto y después de más de diez años de dictadura, irrumpió en el escenario público local y nacional el Boletín del Departamento Pastoral de Derechos Humanos, más conocido como el "Boletín de Derechos Humanos” de Concepción. Este material nos permite aproximarnos a un espacio específico de construcción de identidad, solidaridad y pertenencia, en el cual confluirán dos actores claves del periodo. Por una parte la tarea de la Iglesia Católica a través de la Vicaría de la Solidaridad, en el caso de Concepción a través de la Pastoral de Derechos Humanos ${ }^{2}$ (conocida como la "Vicaría chica") y por otro los familiares de la víctimas de la violación de Derechos Humanos. El trabajo de ambos actores se plasmó a contar de 1986 y hasta 1989 en las páginas del Boletín, el cual se constituyó durante sus años de existencia en un espacio material e inmaterial de resguardo, 
protección y acción no violenta para los perseguidos y sus familias, quienes encontraron en dicho Boletín una oportunidad para construir y canalizar información, opiniones, reflexiones, comentarios y críticas en materia de defensa de los derechos humanos. Aquello posibilito dar respuesta a las dudas y preguntas de quienes fueron afectados; además dio impulso a numerosos relatos sobre la tortura cometida en distintos lugares y espacios de la zona. De esta forma, el Boletín de Derechos Humanos se constituyó en un hito (registro) significativo en la construcción histórica sobre lo que fue el paso de la dictadura cívico-militar en Concepción y sus alrededores.

La encomiable labor humana desarrollada por quienes trabajaron en la edición y difusión del Boletín, ayudó a entregar una cuota de desahogo y esperanza a miles de personas y familiares que desde años buscaban respuesta efectiva sobre el paradero de sus seres queridos. Junto a esto, la labor de la Pastoral de Derechos Humanos, espacio institucional que brindó apoyo a la publicación del Boletín, vino a unir esfuerzos para esclarecer lo sucedido y disipar el manto de dudas, miedo y sufrimiento de miles de ciudadanos penquistas víctimas de la represión.

En vista de lo anterior, el presente trabajo, busca dar cuenta en una mirada de conjunto sobre lo que fue el Boletín de Derechos Humanos de Concepción y su importancia en un espacio local sobre un problema de carácter nacional, como fue la sistemática violación de los Derechos Humanos. De ahí entonces que como hipótesis de trabajo planteemos que el Boletín de Derechos Humanos no sólo cumplió una función en materia comunicacional; es decir, visibilizar la tarea que se estaba realizando internamente en la Pastoral de Derechos Humanos de Concepción, sino también convertirse en un espacio que sirvió de resguardo y resistencia no violenta para los familiares y víctimas de la violencia política institucional de la dictadura.

\section{Antecedentes previos y orígenes del Boletín}

Antes de la aparición de la primera edición del Boletín de Derechos Humanos, la acción de respuesta frente a la persecución y tortura acontecido en Concepción y sus alrededores fue asumida por la Iglesia Católica de Concepción a través del Departamento de Servicio Social, las agrupaciones de Derechos Humanos que a la fecha existían en la zona del Biobío (Vega, 1988 y 1999; Arriagada, Ortega y Palavecino, 2001) y la Revista Solidaridad publicación dependiente del Arzobispado de Santiago y la cual se distribuía por todo el país.

En el terreno de la Iglesia Católica local, la tarea se encarnó en las figuras de monseñor Manuel Sánchez Beguiristain en primer lugar y posteriormente en las de José Manuel Santos Ascarza (Arzobispo de Concepción y Arauco) y el padre Alejandro Goic Karmelic (Obispo Auxiliar) a lo cual se sumaron otros religiosos, como el casa de Carlos Puentes, Enrique 
Moreno, Pedro Azócar, Gabriel Giraud o Cristian Llona, estos últimos en la Parroquia Universitaria. En el caso de Santos y Goic, aparecieron constantemente en los diferentes medios de comunicación, así como en las noticias y artículos referidos a los hechos de violencia que se desencadenaron en incontables oportunidades en las páginas del Boletín. Ejemplo de aquello es el hecho denunciado en 1984 por la Pastoral de Derechos Humanos penquista. Según constata la noticia extraída de Diario El Sur de Concepción, la Pastoral, en 1983 habían recibido el testimonio de 444 personas detenidas producto del clima de violencia que se vivía en el país, con motivo de las jornadas de protestas nacionales (El Sur, 7 de abril de 1984, p. 5). A lo anterior se sumaron las críticas del Arzobispo Santos por los luctuosos incidentes ocurridos en la Vega Monumental (agosto de 1984), donde mueren tres militantes del MIR ("extremistas" en opinión de la prensa), quienes fueron abatidos -según comunicado de la Intendencia- en un "enfrentamiento" con personal de la Central Nacional de Informaciones (CNI). Situación no compartida por el Arzobispo. En opinión de Santos y por testimonios recogidos, estas personas fueron acribilladas por los servicios de seguridad del régimen (Cauce, año 1, número 21, 3 al 9 de septiembre de 1984, pp. 10 a 12). Asimismo la muerte del estudiante de la Universidad de Concepción Caupolicán Inostroza (marzo de 1984), quien fallece a consecuencia de un disparo efectuado por Carabineros, mientras se registraba una jornada de movilización (El Sur, 28 de marzo de 1984, pp. 4,5 y 8).

En aquel contexto de violencia institucionalizada que atravesada la comunidad penquista, la tarea del Arzobispado local tomó distintos significados. Por un lado, desde el clero penquista se insistió en la labor que debía tener todo aquel cristiano en nombre de la paz, libertad y justicia y por otro lado algunos sectores criticaban el actuar de la institución eclesiástica por considerar que no correspondía a la Iglesia tener injerencia en temas de contingencia política, que a su vez eran transversales a cualquier esfera del quehacer en Concepción.

Según lo anterior, existió dentro de la comunidad católica y cristiana penquista opiniones diversas respecto de la labor que comenzó a desarrollar la Iglesia de Concepción -a través de la Pastoral de Derechos Humanosen los temas relacionados con la represión, tortura y desaparición de personas, aquello porque dicho actuar simbolizaba una forma de oposición tacita al actuar represivo del régimen. En otras palabras, la actitud de la Iglesia representaba un modo directo de hacer política de oposición y de resguardo con todas aquellas personas que eran el blanco final de la violencia del régimen (El Sur, 6 de enero de 1984, p. 13).

El hecho que una institución como la Iglesia se constituyera en refugio de quienes eran perseguidos por la dictadura, hacía surgir de menara inmediata una especie de psicosis colectiva en torno al terrorismo y por consiguiente al marxismo. Asimismo, las diferentes reparticiones de la Iglesia en la región del Biobío comenzaron a ser objeto de ataques, insultos y rayados en los que se hacía alusión directa sobre la supuesta filiación entre 
la institución eclesiástica con grupos de inspiración marxistas (El Sur, 5 de junio de 1985, p. 12).

Al respecto, importante recalcar que entre los años 1983 a 1986, el clima de violencia es posible de leerlo con claridad en los registros de prensa local, concretamente en el citado diario El Sur. De la misma forma, la labor efectuada por el Arzobispado penquista comenzó a tomar mayor relevancia cuando estos se constituyen en un intermediario entre la comunidad y las autoridades de la época(El Sur, 5 de abril de 1984, p. 5).

Los siguientes cuadros estadísticos nos permiten tener una visión general sobre los niveles de represión que se vivieron en la zona de Concepción con motivo de las jornadas nacionales de protestas efectuadas en todo el país entre los años 1983 y 1986. Específicamente se muestra los arrestos efectuados entre los años mencionados anteriormente.

Tabla número 1: Cuadro comparativo de arrestos individuales en la zona

\begin{tabular}{|l|c|c|c|c|}
\hline Mes & $\mathbf{1 9 8 3}$ & $\mathbf{1 9 8 4}$ & $\mathbf{1 9 8 5}$ & $\mathbf{1 9 8 6}$ \\
\hline Enero & & 1 & 2 & 3 \\
\hline Febrero & 4 & 5 & 3 & 5 \\
\hline Marzo & 3 & 22 & 5 & 12 \\
\hline Abril & 14 & 5 & 12 & 15 \\
\hline Mayo & 2 & 5 & 1 & 6 \\
\hline Junio & 5 & 4 & & 14 \\
\hline Julio & 1 & 4 & 12 & 13 \\
\hline Agosto & 8 & 13 & 13 & 11 \\
\hline Septiembre & 6 & 6 & 29 & 23 \\
\hline Octubre & 5 & 15 & 4 & 11 \\
\hline Noviembre & 24 & 28 & 45 & 12 \\
\hline Diciembre & 3 & 9 & 9 & 4 \\
\hline Totales & 75 & $\mathbf{1 1 7}$ & $\mathbf{1 3 5}$ & $\mathbf{1 2 9}$ \\
\hline
\end{tabular}

Fuente: Informe Departamento Pastoral de Derechos Humanos, Arzobispado de Concepción, 1987. 
Tabla número 2: Cuadro comparativo de arrestos en manifestaciones colectivas en la zona

\begin{tabular}{|l|c|c|c|c|}
\hline \multicolumn{1}{|c|}{ Mes } & $\mathbf{1 9 8 3}$ & $\mathbf{1 9 8 4}$ & $\mathbf{1 9 8 5}$ & $\mathbf{1 9 8 6}$ \\
\hline Enero & & & 6 & \\
\hline Febrero & & 9 & 6 & \\
\hline Marzo & 11 & 11 & 6 & 7 \\
\hline Abril & 26 & 3 & 25 & 23 \\
\hline Mayo & 29 & 7 & 30 & 70 \\
\hline Junio & 22 & & 5 & 43 \\
\hline Julio & 30 & & 44 & 126 \\
\hline Agosto & 110 & & & 32 \\
\hline Septiembre & 82 & 32 & 111 & 54 \\
\hline Octubre & 46 & 42 & 6 & 64 \\
\hline Noviembre & 9 & 71 & 126 & 6 \\
\hline Diciembre & 4 & 4 & 23 & $\mathbf{4 2 5}$ \\
\hline Totales & $\mathbf{3 6 9}$ & $\mathbf{1 7 9}$ & $\mathbf{3 8 8}$ & \\
\hline
\end{tabular}

Fuente: Informe Departamento Pastoral de Derechos Humanos, Arzobispado de Concepción, 1987.

Tabla número 3: total de arrestos individuales y colectivos en la zona

\begin{tabular}{|l|c|c|c|c|}
\hline Mes & $\mathbf{1 9 8 3}$ & $\mathbf{1 9 8 4}$ & $\mathbf{1 9 8 5}$ & $\mathbf{1 9 8 6}$ \\
\hline Enero & & 1 & 8 & 3 \\
\hline Febrero & 4 & 14 & 19 & 5 \\
\hline Marzo & 14 & 33 & 11 & 19 \\
\hline Abril & 40 & 8 & 37 & 38 \\
\hline Mayo & 31 & 12 & 31 & 76 \\
\hline Juuio & 27 & 4 & 5 & 57 \\
\hline Julio & 31 & 4 & 56 & 139 \\
\hline Agosto & 118 & 13 & 13 & 43 \\
\hline Septiembre & 88 & 38 & 140 & 77 \\
\hline Octubre & 51 & 57 & 10 & 11 \\
\hline Noviembre & 33 & 99 & 171 & 76 \\
\hline Diciembre & 7 & 13 & 32 & 10 \\
\hline Total & $\mathbf{4 4 4}$ & $\mathbf{2 9 6}$ & $\mathbf{5 3 3}$ & $\mathbf{5 5 4}$ \\
\hline
\end{tabular}

Fuente: Informe Departamento Pastoral de Derechos Humanos, Arzobispado de Concepción, 1987. 
Según consignan las noticias aparecidas en la prensa penquista de la época, las relaciones de la Iglesia con el mundo político eran fluidas a pesar de algunos incidentes o altercados que se produjeron, principalmente por el discurso público que adoptó el Arzobispo Santos en materia de derechos humanos. Precisamente por el aumento de la violencia policial y la represión en las protestas -tal y como lo señalan los datos de los cuadros anteriores-, así como el caso de algunas muertes ocurridas durante estos años a manos de la CNI o de la violencia de Carabineros.

En aquel contexto sociopolítico, la aparición del Boletín de Derechos Humanos se constituyó no sólo en la forma de visibilizar públicamente los problemas que se estaban viviendo, sino también dar cuenta de la labor interna que venía desempeñando la Pastoral de Derechos Humanos. Desde temas relacionados con la pobreza, trabajo, salud y educación hasta la represión de la cual eran objetos vastos sectores de la población. De la misma forma, el Boletín se convirtió en un espacio de resguardo y resistencia no violenta a las medidas impulsadas por el régimen pinochetista.

Así fue como en noviembre de 1986 salió a la luz pública el Boletín número 1 de Derechos Humanos dependiente de la Pastoral de Derechos Humanos del Arzobispado de la Santísima Concepción.

El primer número comprendía la quincena del 31 de octubre al 15 de noviembre de 1986. Entre sus primeras informaciones, se hizo mención a la situación de Estado de sitio que imperaba en el país en aquel momento, así como algunos hechos relevantes que habían ocurrido en la zona a propósito de aquella situación. Asimismo, noticias sobre los familiares de exiliados, ataques contra la Iglesia y sobre el Movimiento de Sebastián Acevedo³, entre otras informaciones.

La edición y producción del Boletín estuvo bajo la Unidad de Comunicaciones del Arzobispado. Espacio a cargo de la periodista María Eliana Vega Soto ${ }^{4}$ y quien era la persona encargada junto con Marcelo Cruz de la edición del Boletín 5 .

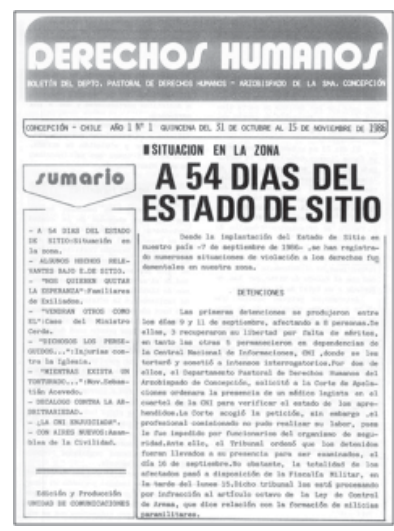

Portada primer número del Boletín de Derechos Humanos, 31 octubre al 15 noviembre de 1986 
María Eliana recuerda que era necesario realizar algo más institucional que diera cuenta de la situación de los derechos humanos donde la Pastoral intervenía

"Le dimos harta vuelta al asunto porque era bien difícil hacerlo, primero por los costos asociados. La Pastoral se financiaba vía proyectos de agencias extranjeras. No teníamos financiamiento directo del Arzobispado, igual que la Pastoral Obrera, entonces para hacer eso teníamos que presentar proyectos y se presentaban proyectos por tres años, que incluían distintos ítem. Entonces el proyecto donde nosotros estábamos, que era el que me financiaba a mí, no contemplaba el Boletín. No lo tenía como parte, entonces había que ver de dónde se sacaba la plata para hacerlo" (Entrevista a María Eliana Vega).

La idea era publicar algo serio y de buena calidad, agrega María Eliana. Incluso, en abril de 1985 se editó un primer Boletín, que en cierta manera fue el antecedente del futuro Boletín de Derechos Humanos. Dicho Boletín se denominó "Informativo Interno” . Se llamó así, porque había que

"resguardarse de una cosa legal. Para poder tu sacar un nuevo medio de comunicación tienes que pedir permiso, no se podía hacer así no más. Había que pedirle permiso a la gobernación y fundamentar bien. Y no te daban permiso para hacer un medio que tuviera que ver con actualidad y contingencia (...) Entonces para que no nos pasara esto que fuera considerado un medio de comunicación con todas las de la ley, nosotros teníamos que buscar una fórmula y una fórmula fuera colocarle informativo interno, aunque se difundiera, pero era interno" (Ibíd).

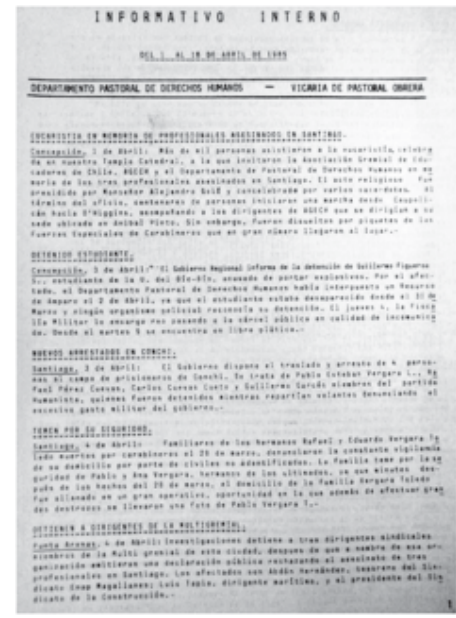

Portada del "Informativo Interno”, abril de 1985 
Este "Informativo Interno" que tuvo un solo número, más otro en formato de revista que se editó en junio de 1985 en conjunto entre la Pastoral de Derechos Humanos y la Pastoral Obrera ${ }^{7}$, constituyeron los antecedentes de lo que un año más tarde sería el Boletín de Derechos Humanos. El objetivo era mostrar lo que se quería hacer. "Si queríamos conseguir la plata, había que mostrar, esto es lo que queremos hacer, son los temas que queremos abordar. Y también queríamos probar un poco si iba a tener o no aceptación dentro de la organización a donde nosotros queríamos llegar”, agrega Vega (Ibíd).

Entonces, el objetivo era llegar a todas las organizaciones de derechos humanos que existían en la zona, las cuales estaban vinculadas con la Pastoral de Derechos Humanos, pero que no contaban con toda la información, puesto que los medios de comunicación tradicionales no difundían o daban a conocer. Además, había un trabajo sistemático que se realizaba en la Pastoral de Derechos Humanos y que al no existir una Unidad de Comunicación era difícil de dar a conocer, tanto a nivel interno de la Iglesia, como a la comunidad en general. A lo más se informaba a través de comunicados, notas de prensa o entrevistas. En vista de lo anterior, la abogada Martita Wörner, el padre Carlos Puentes, María Eliana Vega y Marcelo Cruz coincidieron y acordaron en la idea de realizar algo más institucional para llegar a las organizaciones de Derechos Humanos, la sociedad civil y también a la Iglesia misma, léase parroquias, movimientos apostólicos y comunidades de base. Había llegado el momento de "mostrar lo que estaba haciendo en concreto la Pastoral por defender situaciones, en que casusa estaba involucrada, donde estaba trabajando para defender los derechos de las personas que estaban siendo violentadas" (Ibíd).

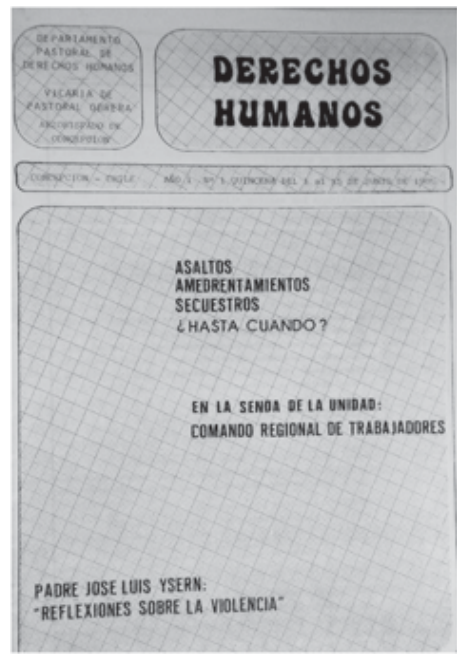

Portada de "Derechos Humanos”, junio de 1985 


\section{Espacios de resguardo y resistencia no violenta}

Adentrarse en el estudio del Boletín de Derechos Humanos, nos lleva a plantearnos dos perspectivas de análisis, por una parte está la forma que tomó el espacio de la Iglesia en Concepción, no solo por el aspecto material donde se encuentra ubicada (centro de la ciudad, frente a la Plaza Independencia), sino más bien la importancia de ésta desde el punto de vista simbólico y reserva moral. De cierta manera, la imagen proyectada por la Iglesia como institución hizo que se generara psicológicamente en las personas una imagen de resguardo y acogida, un frente de acción política a través de los lazos de unión entre familiares de quienes se encontraban detenidos o desaparecidos. Es decir, la Iglesia a través de la Pastoral de Derechos Humanos se convirtió en un espacio de identidad, pertenencia y solidaridad entre quienes concurrieron a pedir ayuda, auxilio y apoyo, no sólo espiritual, sino también emocional y material. Y por otro lado, en dicho espacio se construyó entre quienes allí trabajaban, participaba y asistían un léxico común a la situación vivida, más aún con los términos como el de tortura, violación, represión y desaparición.

En este sentido, la acción que desarrollaron las agrupaciones de los familiares y víctimas de la represión y tortura para dar respuesta al vacío dejado por la duda y el miedo se tradujeron en funciones psicológicas específicas y reciprocas que finalmente convergieron materialmente en el Boletín de Derechos Humanos como un espacio de resguardo y resistencia no violenta. Lo anterior permitió, a través de un esfuerzo en conjunto (Iglesia-Pastoral de Derechos Humanos y familiares), romper con el cerco de aislamiento comunicacional impuesto por la dictadura a través del miedo, logrando con aquello articular un lenguaje común en torno a la figura de la tortura, desaparición y violación de derechos humanos cómo práctica sistémica del régimen.

Al respecto, Simmel (1987) plantea que existe un vacío entre personas que viven aisladas dentro de determinados límites espaciales. Dicha relación se hace presente en el hecho de que las personas perseguidas por la dictadura conformaron un frente de acción para romper aquella relación de aislamiento producto del miedo y las dudas acerca del paradero de sus familiares y seres queridos. En este sentido, la acción reciproca que sucede entre los familiares y la Iglesia Católica de Concepción pasa a dotar de un elemento espiritual vasto en cuanto a contención y acción frente a las situaciones de atropello que viven las personas afectadas por la violencia del régimen.

Si pensamos en el contexto que rodea los hechos descritos en las páginas del Boletín, nos daremos cuenta que la propia dictadura instituyó la necesidad de que se cree un sentido común entre los familiares y la sociedad sobre dar un uso institucional a la violencia sistemática realizada por sus aparatos represivos, la deformación comunicacional y el alto grado de polarización del discurso sobre los "elementos terroristas" que buscaban -en opinión de la Junta Militar- destruir la nación. Dichos hechos posi- 
bilitaron el trabajo de las organizaciones aún cuando se realizaron diversos allanamientos a cedes pastorales de la provincia. Esto se entendió por el grado de notoriedad que tomaron los hechos de violencia y el miedo por la persecución que se realizó en aquellos años. Reflejo de lo anteriores un reportaje publicado en el Boletín sobre el Movimiento Sebastián Acevedo, en el cual se muestra y se presenta la agrupación dando a conocer la realidad vivida por personas en torno a lo que significó la inmolación de Sebastián Acevedo frente a la catedral de Concepción. Un hecho que más allá de recordar la desesperación, dudas y miedo que pueden gatillar situaciones de violencia diferentes a la coerción física, más bien cercanas al plano psicológico y espiritual de una persona(Boletín Derechos Humanos, año 1, número 1, 31 de octubre al 15 de noviembre de 1986, p. 10).

Que lo anterior fuese llevado en conjunto con la Iglesia no fue de agrado para algunos sectores de la sociedad penquista, puesto que veían como una amenaza el papel que tomaba el clero en materia de derechos humanos, especialmente el Arzobispo Santos y el Obispo Goic. Aquello se materializaba por ejemplo en las constantes acciones de amenazas, amedrentamiento y rayados ofensivos que sufrió el edificio de la Iglesia o de la Pastoral (Boletín Derechos Humanos, año 2, número 5, 1 al 15 de marzo de 1987, p. 10; año 2, número 10, 16 al 31 de mayo de 1987, pp. 2-3; año II, número 23, enero de 1988, p. 3; año III, número 38, enero de 1989, p. 3).

Es el caso del recordado eslogan que aludía a los “Curas Rojos” o bien otras consignas tales como "Militares al gobierno. Curas rojos (CamusGoic) al infierno” (Boletín Derechos Humanos, año 2, número 5, 1 al 15 de marzo de 1987, p. 10). También de reiteradas amenazas por parte de elementos simpatizantes del régimen: La Asociación Chilena Anticomunista (ACHA) y La Juventud de Avanzada Nacional (JAN) (Boletín Derechos Humanos, año II, número 24, 15 al 31 de marzo de 1988, p. 5). Siendo uno de los puntos más graves, los atentados del cual fue objeto el vicario Carlos Puentes. El primero el mes de abril de 1987 y el segundo en diciembre del mismo año. En ambas ocasiones se incendió vehículos de su propiedad (Boletín Derechos Humanos, año 2, número 10, 16 al 31 de mayo de 1987, p. 3, y año II, número 22, 16 al 31 de diciembre de 1987, pp. 6 a 8).

Respecto a la persecución, parece preciso resaltar el hecho que el primer número del Boletín contenga un decálogo sobre la arbitrariedad, el cual puede ser considerado como una especie de manual de acción cuando una persona es arrestada o bien sufre algún tipo de agresión bajo la instauración del Estado de Sitio el 8 de septiembre de 1986. Algunas de las aclaraciones aparecidas consignaban lo siguiente:

"Por un lado, el asesinato con características de ajusticiamiento de cuatro personas con que se inicia un nuevo periodo de excepción. Por otro, el modo en que los servicios policiales y de seguridad actúan en cumplimiento de órdenes administrativas o judiciales. Finalmente el seguimiento, vigilancia y amedrentamiento a personas por parte de grupos de origen aún desconocido” (Boletín Derechos 
Humanos, año 1, número1, 31 de octubre al 15 de noviembre de 1986, p. 11).

Según se puede apreciar, la situación vivida es bastante difícil de sostener cuando no se puede asegurar de forma cierta quienes son los perpetradores y a que institución pertenecen, aunque de una forma u otra la responsabilidad recaía en los organismos de seguridad, como lo era la CNI. Por la misma razón, dicho decálogo aconsejaba una serie de pasos sobre qué hacer y cómo actuar en caso de ser detenido o estar en presencia de alguna detención irregular. Por ejemplo, exigir identificaciones y órdenes de detención; identifíquese en voz alta, gritar o llamar la atención para que los testigos llamen a Carabineros o Investigaciones; avisar a familiares o que acudan a la Vicaría de la Solidaridad. En caso de ser detenido irregularmente o secuestrado, intentar calcular el trayecto del viaje, las características del lugar al que es llevado y la mayor cantidad posible de datos, entre otras cosas (Boletín Derechos Humanos, año 1, número 1, 31 de octubre al 15 de noviembre de 1986, p. 11).

No existe duda que lo narrado en el Boletín pasó a constituir una acción tendiente a enfrentarlos atropellos de los derechos humanos en la zona de Concepción. Un espacio donde diversos actores sociales y políticos junto a la Iglesia Católica dieron resguardo y férrea oposición en contra de la política represiva que instauro la dictadura de Pinochet.

\section{Personas y apoyo mutuo}

Sin duda la violencia, el enfrentamiento, el conflicto social y político, así como el miedo fueron parte significativa del contexto que vivió gran parte de la el país y la población penquista durante los años ochenta. No son pocos tampoco los casos donde el espacio público se convirtió en escenario de violentas acciones por parte de funcionarios vinculados a los organismos represivos de la época. Ese mismo espacio se convirtió con el transcurrir de los años en el mejor patrocinador de la forma como se visibilizaron dichas situaciones; más importante aún por que incluían a un sector de la población marcada por el estigma de la persecución y por tanto las relegaba y estigmatizaba bajo la imagen de ser un foco peligroso del marxismo en contra del régimen autoritario.

Lo anterior nos hace pensar en diferentes formas sobre cómo abordar dichos hechos desde el presente, aquello por el inmerso esfuerzo que se realizó para concretar una forma de resistencia no violenta, usando el perfil ético y moral que tenia para gran parte de la población la Iglesia Católica de la época, más aún por la importancia concedida por el régimen en el plano espiritual donde los modelos de vida y comportamiento moldeaban el deber ser de la sociedad. Por este motivo, la Iglesia de Concepción actuó entre los límites de lo permitido por la dictadura por ser ella una institución ética y moral de gran impacto sobre la defensa del ser humano en su conjunto. Así, el proceso de disciplinamiento y control social que buscó la dictadura du- 
rante los ochenta pudo ser eludido por la Iglesia Católica en su relación con las víctimas del régimen, para de esa forma crear una zona de resguardo, contención y apoyo a quienes vivían situaciones de atropello en sus derechos fundamentales.

Pero aquella forma de plantear una solución para los perseguidos por la dictadura también significo afrontar para el Arzobispado de Concepción situaciones complejas de confrontación directa con quienes eran las autoridades de la zona. Y es que durante 1986 el clima y las relaciones entre la Iglesia y la Intendencia del Biobío, representadas en su máxima autoridad, Eduardo Ibáñez Tillería no eran las mejores.

Hace ya tres años que en Concepción no se celebraba un TeDeum con motivo de las fiestas patrias, aquello constituía una grave ofensa para la imagen de autoridad que buscaba proyectar la dictadura. Como detalla Diario El Sur en septiembre de 1986, en una carta respuesta a la petición de realizar el TeDeum, el Arzobispo Santos rechazó dicha petición señalando que se había extendido una invitación especial a la misa que de igual manera se celebraría en la catedral de Concepción con motivo del 18 de septiembre, “...no obedecía a una menor estimación a su persona (el intendente) -de quien siempre me he expresado bien- sino a las reiteradas irregularidades cometidas contra la Iglesia a la que represento”, señaló Santos. Finalmente y luego de referirse a algunos puntos sobre la violencia en contra de personas, inmuebles de la Iglesia que habían sido denunciados pero no resueltos, el Arzobispo de Concepción se preguntó “¿Cómo aparentar ante una comunidad con tantos sufrimientos que no ha sucedido nada?”. Frente a estas respuestas el Intendente Regional, respondió a través de la prensa que no habrá una respuesta para la negativa del Arzobispo, de igual forma señaló que “...para tener realmente una convivencia dentro de todas las actividades de la región, considero que debemos, de alguna forma, dejar de lado ciertas cosas, que pueden suavizarse. Especialmente, que yo no tengo nada personal con él y creo que él debe pensar en la misma forma”. Aún así el Intendente señalaría que de todas formas para esa fecha se realizaría a las 11 horas, su propio TeDeum "como en todos los años en que ha habido problemas con el señor Arzobispo” (El Sur, 6 de septiembre de 1986, p. 13).

El potente mensaje que había construido el Arzobispado de Concepción era un recordatorio lo suficientemente fuerte para ser captado como una muestra desafiante del compromiso que tuvo la Iglesia local durante la administración de monseñor Santos Ascarza.

Este incidente por él TeDeum, graficaba de buena forma las tensionantes relaciones que se vivían por aquellos días entre la autoridad eclesiástica y la autoridad política y militar de la zona. Asimismo, el Arzobispo dio a conocer -en otras ocasiones- de manera bastante clara y directa su opinión respecto a la situación de violencia y represión que por aquellos años se vivían en el país y en la zona de Concepción (El Mercurio, La Tercera de la Hora y Las Ultimas Noticias, 16 de septiembre de 1984). 
Santos expresó que reemplazar él Te Deum por una misa se enmarcaba en una serie de problemas que se habían venido desarrollando entre el gobierno y la Iglesia. Agregando "imagínese lo que significa para mi ir a dejar al intendente a la puerta de la Iglesia”, pero no solamente aquello "Figúrese: ir a dejar a la puerta del templo al general de Carabineros que me tira bombas al interior de la Catedral; ir a dejar al presidente de la Corte que ha denegado un ministro en visita, ¿no encuentra usted que es hipócrita eso? A mí, honradamente, me parecería una hipocresía” (El Mercurio, 16 de septiembre de 1984, p. 4).Esos desencuentros, en apariencia diplomáticos, fueron graficados fielmente también en las páginas del Boletín de Derechos Humanos.

\section{Derechos humanos en clave local}

El trabajo realizado por el Boletín durante sus años de publicación, logró plasmar y visibilizar de una manera directa todos aquellos hechos que se relacionaron con la sistemática violación de derechos humanos ocurridos en la zona y que carecieron de cobertura o bien fueron omitidos por la prensa local y nacional. En ese sentido, la idea original del Boletín era sintetizar y difundir el trabajo que hacia la Pastoral de Derechos Humanos, lo que estaba ocurriendo en la zona, proporcionar información a las diversas agrupaciones de Derechos Humanos y que ojalá la ciudadanía pudiera informarse de aquellos temas que los medios oficiales omitían o no publicaban.

En ese sentido, cabe destacar que el mismo Boletín cuenta en sus páginas con variada información respecto de aquellos hitos que marcaban el acontecer diario, lo cual posibilitó a quienes lo leyeran, tener un panorama claro y preciso sobre los actos de violencia de la dictadura y las acciones de denuncia (resistencia pacífica) de parte de los miembros de las agrupaciones de familiares de detenidos desaparecidos y víctimas de la represión.

En ese contexto, existe consenso sobre el papel que desempeñó la Iglesia Católica de Concepción a través de la Pastoral de Derechos Humanos, asumiendo la tarea de resguardo y protección a quienes eran perseguidos y de un permanente llamado a la justicia y reconciliación entre los chilenos, sean estos partidarios o contrarios al régimen. A su vez la Iglesia se transformó en un espacio que aunó criterios y forjó lazos de solidaridad, sobre la base de un léxico común frente a la persecución llevada a cabo por la dictadura. De ahí es posible ver y leer en el propio Boletín noticias y entrevistas con declaraciones de algunos religiosos en una clara postura de crítica y oposición a las medidas impulsadas por la dictadura(Boletín Derechos Humanos, año 1, número 3, 1 al 15 de diciembre de 1986, pp. 10-11; año 2, número 9, 1 al 15 de mayo de 1987, pp. 8-9; año 2, número 10, 16 al 31 de mayo de 1987, pp. 6 a 8; año 2, número 11, 14 al 27 de junio de 1987, pp. 6-7; año 2, número 18, 1 al 17 de octubre de 1987, pp. 4-5; año II, número 25, 4 al 21 de abril de 1988, pp. 11-12). 
Es el caso por ejemplo del Obispo de Linares, monseñor Carlos Camus, quien señaló que la labor que debían cumplir los obispos en momentos en los cuales aumentaba la represión era la de hablar, cuando otros no podían hacerlo (Boletín Derechos Humanos, año II, número 24, 15 al 31 de marzo de 1988, p. 11). La Iglesia de Concepción pasó a desempeñar una función social primordial al prestar resguardo desde el primer momento. No sólo aquello, también a la hora de efectuar una crítica al modelo económico que impuso la dictadura (Boletín Derechos Humanos, año 2, número 16, 1 al 15 de septiembre de 1987, pp. 6 a 8; año 2, número 18, 1 al 17 de octubre de 1987, pp. 6 a 8; año 2, número 9, 1 al 15 de mayo de 1989, pp. 3-4; año III, número 38, enero de 1989: 8; año III, número 39, pp. 6-7)

El Boletín acentuó sus críticas y denuncias frente al momento que se configura en la región durante los últimos años de los ochenta. Visibiliza el malestar de la población y dio espacio a las acciones no violentas que impulsaron las distintas organizaciones contra el régimen. Se abordan temas desde diversas áreas del acontecer local y nacional pudiendo lograr una respuesta positiva en cuanto al uso que buscaba tener el Boletín. Inclusive se realizó una encuesta preguntando por la utilidad y diversos tópicos referentes al Boletín, cómo también sobre el documento Hoja Mural, que era un texto de una carilla, el cual se adjuntaba dentro de cada ejemplar del Boletín (Boletín de Derechos Humanos, año II, número 25, 4 al 21 de abril de 1988).

El objetivo de dicha Hoja era resumir determinada información para posteriormente ser exhibida en diversos lugares de la ciudad. De esta forma, se buscaba llegar a un mayor número de personas con información breve y directa de lo que estaba pasando en materia de Derechos Humanos. De ahí entonces la importancia del Boletín a la hora de sistematizar la información con la cual contaba la Pastoral de Derechos Humanos, en su sección jurídica, para posteriormente darla a conocer a la opinión pública local, regional y nacional.

Ese fue el caso, por ejemplo de lo que aconteció en la Universidad de Concepción. Al interior de las páginas del Boletín se dio cobertura a la participación de académicos y estudiantes en diversas actividades que se llevaron a cabo con motivos de las movilizaciones de la época. Al respecto, el Boletín del mes de mayo de 1988 consigna lo siguiente "El 6 de mayo, 708 académicos de un total habilitado de 874, participaron en una consulta llamada por la Federación Gremial de Académicos con el objeto de pronunciarse sobre tres aspectos”. En primer lugar la suspensión temporal del paro. Lo cual fue aprobado por 616 académicos. En segundo lugar, el rechazo a cualquier amenaza, sanción o presión contra los académicos, así como el respaldo a la conducción de los dirigentes. Aprobado por 543 académicos. Por último, instar a los decanos para que desempeñen un papel más activo en la crisis universitaria. Moción aprobado por 595 académicos (Boletín Derechos Humanos, año II, número 27, 15 al 31 de mayo de 1988, pp. 10-11). 
Hacia fines de 1988 y en su constante labor de defensa de los Derechos Humanos, la Iglesia de Concepción realizó un público llamado para que se conversara lo que pasaba con miles de chilenos que viven una cruda e injusta realidad. Desde aquellos que son víctimas de la persecución, hasta quienes son vulnerados en sus derechos más básicos por un sistema económico que los excluye o explota. Al mismo tiempo, impulsó Programas de Educación Cívica para la participación de los ciudadanos y además, realizó un público llamado para que las personas se inscribieran en los registros electorales y concurrieran a votar en el plebiscito de 1988 (Boletín Derechos Humanos, año 2, número 12, 28 de junio al 12 de julio de 1987, pp. 1-2; año 2, número 14, 29 de julio al 16 de agosto de 1987, pp. 1-2; año 2, número 19, 26 de octubre al 10 de noviembre de 1987, pp.1-2; año II, número 27, 15 al 31 de mayo de 1988, p. 2).

Es ahí entonces donde radica la importancia del Boletín, poner de manifiesto una situación de contingencia desde la no violencia, permitiendo de esta manera la coexistencia de un gran número de personas en el mismo momento. Su relato y su historia se constituyeron en una imagen común para todos aquellos que no podían atravesar el cerco informativo que mantuvo y reprodujo la dictadura durante los años que lleno de temor y miedo la vida cotidiana de los chilenos, entre ellos los de Concepción y sus alrededores.

\section{Comentarios finales}

Uno de los aspectos centrales durante la dictadura cívico-militar fue la forma de cómo pensar algunas redes o formas de comunicación que permitieran dar cuenta y visibilizar el trabajo que se estaba realizando al interior de la Iglesia Católica y que se relacionaba con el tema de la protección a las víctimas de la violación a los derechos humanos. Concretamente la tarea que realizaba la Vicaría de la Solidaridad, más aun en un contexto donde se imponía la censura y una absoluta falta de libertad de expresión.

Si bien la irrupción de prensa y revistas alternativas desde fines de los años setenta (Hoy, Análisis, Apsi, Cauce y Fortín Mapocho entre otras), sumado a la tarea que desempeñó la Revista Solidaridad, dependiente de la Vicaría en Santiago, estaban contribuyendo a dar cuenta y denunciar las políticas de represión y los crímenes de la dictadura, lo ocurrido en regiones y provincias seguía invisibilizado y oculto para gran parte del país.

En ese contexto, la aparición en 1986 del Boletín de la Pastoral de Derechos Humanos del Arzobispado de la Santísima Concepción, se constituyó en un acontecimiento de suma importancia, no sólo en materia informativa o comunicacional, sino para la propia Iglesia penquista, los familiares y agrupaciones de derechos humanos y la población en general.

Pero no fue solamente aquello. El Boletín se constituyó en un dispositivo clave, cumpliendo una doble función. Por una parte ser una espacio 
de reguardo, donde se daría cabida a aquellas voces que durante años habían estado en el anonimato o que el discurso oficial y hegemónico de la dictadura los había invisibilizado o silenciado. Un espacio que dio cabida en sus páginas no sólo a quienes sufrieron la represión física del régimen, léase detenciones, tortura, desapariciones y asesinatos, sino también a quienes eran víctimas de la violencia de un sistema económico como el neoliberal que generaba cesantía, exclusión, explotación y abuso.

La otra función del Boletín fue asumir un discurso de denuncia e interpelación a las autoridades de la época; es decir, ser un espacio de resistencia no violenta ante una dictadura que tenía como impronta el uso de la violencia en su más amplia acepción.

Pero la importancia del Boletín no se circunscribió sólo aquello. A través de sus páginas se pudo dar cuenta de la situación de violencia institucional que se experimentó fuera de la capital Santiago, es decir en regiones, provincias y ciudades donde el conflicto sociopolítico se vivió de manera traumática y con graves consecuencias para la población. Fue el caso de lo ocurrido en Concepción y la región del BíoBío.

Cifras sobre el número de personas detenidas, comentarios y entrevistas de religiosos, a familiares de víctimas de la represión, crónicas y reportajes sobre la situación laboral, en materia de salud, vivienda y trabajo, así como la escenario que ocurría en la Universidad de Concepción y los ataques a la Iglesia, hasta llamados a la participación política, con motivo del plebiscito de 1988 fueron algunos de los tópicos que circularon constantemente en las páginas del Boletín.

De ahí entonces su importancia y trascendencia histórica. Haberse convertido en poco tiempo en un espacio de resguardo y resistencia no violenta para quienes desde años habían sufrido precisamente la violencia sistémica de un régimen dictatorial en un espacio local, como fue Concepción y sus alrededores.

Contrarrestar el discurso hegemónico de la dictadura y las informaciones de una prensa proclive al régimen, no fue tarea fácil, más aun siendo de regiones y con los escasos recursos y personal humano con el que se contaba. Pero en aquellos complejos años, más que el dinero o el número de personas, estaban presentes otras variables que en cierta medida constituían el baluarte de la resistencia al régimen.

Solidaridad, fraternidad, identidad, sentido de pertenencia, consecuencia y consistencia en buscar siempre la verdad y la justicia se convirtieron tras el golpe de Estado de 1973 en los mejores baluartes de quienes con los años lograron dar vida al Boletín de Derechos Humanos en Concepción, como uno de los espacios característicos de resguardo y resistencia no violenta contra la dictadura cívico-militar de Augusto Pinochet. 


\section{Notas}

${ }^{1}$ El presente artículo se enmarca en el proyecto Fondecyt regular número 1150049.

${ }^{2}$ El 16 de marzo de 1976, a través del Decreto 556 el entonces Arzobispo de Concepción y Arauco Monseñor Manuel Sánchez creo el Departamento de Servicio Social del Arzobispado de Concepción. Su objetivo fue prestar ayuda a todos quienes estaban siendo afectados por las políticas represivas de la dictadura. Siete años más tarde, en febrero de 1983 y por medio del Decreto número 805 el Departamento de Servicio Social pasó a denominarse Pastoral de Derechos Humanos del Arzobispado de la Santísima Concepción, siendo su Director Eclesiástico el Padre Carlos Puentes Figueroa y la abogada Martita Worner Tapia como Directora Ejecutiva.

${ }^{3}$ El 11 de noviembre de 1983, se inmola quemándose a lo bonzo, Sebastián Acevedo Becerra, un obrero de la construcción de 50 años de edad. Desesperado por no saber dónde estaban sus hijos detenidos por personal de la Central Nacional de Informaciones, adoptó la determinación luego de agotar todos los medios para dar con el paradero de sus hijos Galo y María Candelaria. La acción la consumó en las escalinatas de la Catedral de Concepción.

Sebastián Acevedo quedó con el 90\% de su cuerpo quemado, falleciendo horas más tarde. Dicha acción dio origen posteriormente al "Movimiento Contra la Tortura Sebastián Acevedo”.

${ }^{4}$ María Eliana Vega Soto, nació en Coelemu. Realizó sus estudios de enseñanza básica y media en dicha localidad. El año 1979 ingresó a estudiar periodismo en la Universidad Católica de Santiago, titulándose de periodista el año 1983. El año 1982, realizó su práctica profesional en diario El Sur de Concepción. A fines de 1983 ingresó a trabajar al vespertino Crónica de Concepción. Posteriormente se desempeñó como reportera de la "Gaceta del Bío-Bío", un suplemento dominical que editaba diario El Sur los días domingo. Finalmente el año 1985 es llamada por el vicario Carlos Puentes y la abogada Martita Worner quienes trabajaban en el Departamento Pastoral de Derechos Humanos. Su tarea fue encargarse del programa de comunicaciones de la Pastoral, momento en el cual se hace cargo de editar el Boletín de Derechos Humanos del Arzobispado de la Santísima Concepción entre los años 1986 y 1989.

${ }^{5}$ La Unidad de Comunicaciones tenía un carácter educativo e informativo, tendiente a dar a conocer y difundir el trabajo que se realizaba en el Departamento y la Iglesia Católica del Biobío. Asimismo, cubrir la falta de información objetiva en materia de Derechos Humanos

\footnotetext{
${ }^{6}$ Aquella única edición, incluyó un recuento del asesinato de los dirigentes comunistas José Manuel Parada, Santiago Natttino y Manuel Guerrero ocurrido el 30 de marzo de 1984. Además, una nota sobre el Campo de prisioneros de Conchi e información sobre la negociación colectiva del Sindicato Petrox y el $1^{\circ}$ de Mayo día del Trabajador. En total fueron 16 páginas formato carta, escritas a máquina e impresas en off set.
}

${ }^{7}$ Este segundo Boletín llamado "Derechos Humanos” fue de 30 páginas tamaño doble carta. En su única edición incluyó noticias sobre derechos humanos y del mundo de los trabajadores. Además, incluyó un reportaje sobre los últimos hechos de violencia ocurridos en la zona como por ejemplo el caso de Tatiana Fariña, el asesinato de Rodrigo Randolph, la agresión al sacerdote Manuel Hervia, y la violación de la estu- 
Polis, Revista Latinoamericana, Volumen 15, $N^{\circ}$ 43, 2016

diante Paz Macaya. También traía una reflexión del padre José Luis Ysern sobre la violencia, la cual fue expuesta en el Colegio Médico de Concepción. Por último una nota sobre el Comando Regional de Trabajadores de la zona. 


\section{Bibliografía}

Araujo, Kathya y Martuccelli, Danilo (2012), Desafíos comunes. Retrato de la sociedad chilena y sus individuos, Lom ediciones, Santiago.

Arriagada, Lucía, Ortega, Marianela y Palavecino, Giuliana (2001), La Iglesia Católica en defensa de los derechos humanos durante el régimen militar, en Concepción. Concepción, Tesis para optar al grado de Licenciado en Educación, mención Historia y Geografía.

Brunner, José Joaquín (1977), De las experiencias de control social, Flacso, Santiago.

Brunner, José Joaquín (1980), Ideología, legitimación y disciplinamiento en la sociedad autoritaria, Flacso, Santiago.

Díaz, Viviana, Sierra Sola y Becerra, Gustavo(1997), 20 años de historia de la Agrupación de Familiares de Detenidos Desaparecidos de Chile, Neoprint, enero, Santiago.

Errázuriz, Luís Hernán y Leiva, Gonzalo (2012), El golpe estético. Dictadura militar en Chile, 1973-1989, Ocho libros, Santiago.

Garretón, Manuel Antonio, Garretón, Roberto y Garretón, Cármen (1998), Por la fuerza sin la razón. Análisis y textos de los bandos de la dictadura militar, Lom ediciones, Santiago

Insunza, Andrea y Ortega, Javier (2011), Los archivos del Cardenal. Casos reales, Catalonia, Santiago.

Insunza, Andrea y Ortega, Javier (2014), Los archivos del Caerdenal 2. Casos reales, Catalonia, Santiago.

Lechner, Norbert (2006), Obras escogidas, Lom ediciones, Santiago.

Monsálvez Araneda, Danny (2014), Los bandos militares en Concepción y Talcahuano. Disciplina militar y disciplinamiento social, Ediciones Escaparate, Concepción.

Orellana, Patricio y Hutchison, Elizabeth (1991), El movimiento de derechos humanos en Chile, 1973-1990, Centro de Estudios Políticos Latinoamericanos Simón Bolívar, Santiago.

Padilla, Elías (1995), La memoria y el olvido. Detenidos desaparecidos en Chile, Ediciones Orígenes, Santiago.

Peñaloza, Carla (2011), Memorias de la vida y la muerte. De la represión a la justicia en Chile, 1973-2010. Barcelona, Tesis Doctoral en Historia, Universitat de Barcelona. 
Polis, Revista Latinoamericana, Volumen 15, $N^{\circ}$ 43, 2016

Rebolledo, Javier (2012), La danza de los cuervos. El destino final de los detenidos desaparecidos, Ceibo ediciones, Santiago.

Rebolledo, Javier (2013), El despertar de los cuervos. Tejas verde, el origen del exterminio en Chile, Ceibo ediciones, Santiago.

Rebolledo, Javier (2015), A la sombra de los cuervos. Los cómplices civiles de la dictadura, Ceibo Ediciones, Santiago.

Salazar, Manuel (2011), Las letras del horror. Tomo I: La DINA, Lom ediciones, .

Salazar, Manuel (2012), La letras del horror. Tomo II: La CNI, Lom ediciones, Santiago.

Simmel, George (1987). Sociología. 2. Estudios sobre las formas de socialización,Alianza Editorial, España.

Vega, María Eliana (1988), Por la sagrada dignidad del hombre. 15 años de defensa y promoción de los derechos humanos, Departamento Pastoral de Derechos Humanos, Concepción.

Vega, María Eliana (1999), No hay dolor inútil. La Iglesia de Concepción y su defensa de los derechos humanos en la región del BíoBío entre 1973 y 1991. Relato de los casos más impactantes ocurridos en la zona en ese período, Departamento de Pastoral Obrera Arzobispado de la Santísima Concepción - Agrupación de Familiares de Detenidos Desaparecidos Región del BíoBío, Concepción.

Weibel, Mauricio y Dorat, Carlos (2012), Asociación ilícita. Los archivos secretos de la dictadura, Ceibo ediciones, Santiago.

\section{Prensa y revistas}

Informativo Interno. Departamento Pastoral de Derechos Humanos, Vicaría Pastoral Obrera, 1 al 16 de abril de 1985, 16 páginas.

Derechos Humanos. Boletín Departamento Pastoral de Derechos Humanos, Vicaría de Pastoral Obrera, año 1, número1, quincena del 1 al 15 de junio de 1985, 30 páginas.

Boletín de Derechos Humanos de la Pastoral de Derechos Humanos, Arzobispado de la Santísima Concepción, año 1, número 1 del 31 de octubre al 15 de noviembre de 1986 al año III, número 44, agosto de 1989.

Diario El Sur de Concepción, año 1978 a 1989.

El Mercurio, 16 de Septiembre de 1984. 
La Tercera de la Hora, 16 de septiembre de 1984.

Las Ultimas Noticias, 16 de septiembre de 1984.

Revista Cauce, año 1, número 21, semana del 3 al 9 de septiembre de 1984.

Informe Departamento Pastoral de Derechos Humanos, Arzobispado de Concepción, 1987.

\section{Entrevista:}

María Eliana Vega Soto: periodista y editora del Boletín de Derechos Humanos de la Pastoral de Derechos Humanos del Arzobispado de la Santísima Concepción, 1986 a 1989.

Recibido: 30.01.2016

Aceptado: 05.04.2016 